Fecha de recepción: abril 2019

Fecha de aceptación: octubre 2019

Versión final: mayo 2020

\section{La imagen visual de la identidad, entre resistencias y representaciones hegemónicas}

María Ximena Betancourt Ruiz *

Resumen: La imagen-representación, aceptada socialmente y sin mayor mediación, como símbolo de re-conocimiento del mundo real, tiene en la marca o logo un signo de identidad visual que se despliega en múltiples aspectos y capacidades: identifica, diferencia, ampara intereses, interactúa socialmente y es discurso al que le subyacen intereses y estrategias de diferente índole. Asumida a modo de sustituto de la realidad, la marca es una de las imágenes articuladas con mayor cobertura en la contemporaneidad, abarca además de entidades comerciales, los territorios, los sujetos, su identidad y sus acciones por medio de homogeneizaciones en el marco del sistema capitalista, convirtiéndose en fuertes herramientas del poder. Actualmente este signo es figuración, cosificación; acaso más complejo, pues mediado por las tecnologías de la imagen, no sustituye una realidad, la simula, incluso, la anticipa desde su inexistencia, dando pié a innovadoras formas de dominación simbólica que propenden por la diversidad, mientras acentúan la negación de la "alteridad". En esta relación con el territorio, el mercado y sus marcas, el individuo de finales del s. XX y principios del s. XXI, ha construido nuevas relaciones con lo visible que configuran nuevas formas identitarias y posibilitan tanto la sumisión, como la emergencia de resistencias.

Palabras clave: imagen - representación - diversidad - alteridad - identidad.

[Resúmenes en inglés y portugués en las páginas 73-74]

${ }^{*}$ Docente Asociado II Universidad de Bogotá Jorge Tadeo Lozano, Diseñadora Gráfica, Especialista en Pedagogía de la comunicación y medios interactivos y Magister en Comunicación Educación, Doctoranda en Estudios Sociales de la Universidad Externado de Colombia.

\title{
Introducción
}

Este ensayo se enmarca en el componente visual de las representaciones que se hacen actualmente de los territorios, específicamente de Colombia y de los colombianos, otorgando a la imagen ${ }^{1}$ la categoría de agente ${ }^{2}$ en la construcción de identidades ${ }^{3}$ tanto dominantes como emergentes, a través de los estudios sociales y las semióticas visuales ${ }^{4}$, desde donde se propone la identificación e interpretación de los diferentes niveles de valoración 
identitaria ${ }^{5}$ que se dan en Colombia, para abrir la posibilidad de otras propuestas de apreciación, diseño y gestión coherentes e incluyentes con la realidad actual del país.

Surge del interés de los resultados arrojados por el Estado del Arte de investigaciones propias previas y actuales, que mostró un vacío de conocimiento en los Estudios Sociales sobre el impacto de las imágenes visuales que representan la identidad colombiana y en general escasos estudios alrededor de la marca territorio como imagen mediación entre el yo, el tu y el nosotros en la contemporaneidad. En consecuencia, se parte de perspectivas vigentes del campo de los estudios sociales, que facilitan la comprensión del contexto. Posteriormente, desde una perspectiva semiótica, se relacionan con el campo de los estudios visuales para, en espacios interdisciplinarios, encontrar lógicas correlacionales diferentes a las establecidas por la institucionalidad que permitan identificar puntos de identidad país relevantes.

Se realiza una revisión y análisis de la identidad en la lógica de la imagen y los imaginarios $^{6}$ como constructores sociales en pro de reconsiderar, reconocer y potenciar el valor social de la imagen visual como mediadora y productora de identidad. Se reconoce que la representación ocurre a través de una serie de negociaciones que se dan en diferentes dimensiones expresando las diferencia y el pluralismo propios de la identidad. Por ello la comprensión de los imaginarios urbanos es necesaria pues éstos son un registro sensible de esta complejidad.

El desarrollo de este acercamiento a la imagen representación de identidad atraviesa cinco categorías que permiten la comprensión del problema: la primera desarrolla la necesidad de representarse para ser reconocido, resaltando la importancia del surgimiento y desarrollo de la marca territorio y cuestionando su verdadero valor identificatorio. La problematización reconoce un contexto que se define como espacio de lucha por el reconocimiento, en donde el poder de la identidad ofrece un punto de ruptura con el sistema dominante (Robertson \&Pineda, 1998), por ello se harán evidentes las tensiones entre las representaciones dominantes y las representaciones emergentes a través de los imaginarios globales del "nosotros" en choque con los imaginarios regionales y locales. La segunda parte desarrolla una breve contextualización de los análisis y propuestas de reconocimiento identitario que se han producido en el contexto nacional y en el internacional. La tercera parte aborda y justifica las posiciones teórico conceptuales desde las cuales es posible entender, argumentar y cuestionar el poder y el sentido de la marca como imagen visual material que potencia las representaciones de territorio y el juego que se da entre imaginarios y representaciones en un plano cibercultural, contextual mediatizado.

\section{La necesidad de representarse para ser reconocido}

Las representaciones visuales, marcas del país emitidas desde el poder de centro, adicional a los objetivos exógenos propios de este tipo de imagen, construyen imaginarios de identidad nación, buscan suscitar sentimientos de pertenencia por parte de sus habitantes locales y adhesión por parte de los foráneos. Su gestión política y económica, afecta todos los ámbitos de la vida: Identifican, descubren o niegan identidades; por ende, aunque su aparición supone solo el figurar en los entornos comerciales, su proyección en todos los 
ámbitos de la vida, afecta directamente a los individuos y sus prácticas culturales y sociales, incidiendo en sus acciones.

Lejos del interés por el medio y en el mismo sentido por el contenido en tanto captura del mundo, la imagen deviene en un rastro, en una pista para la comprensión del algo mayor. Nada tiene que ver con que tenga valor iconográfico, o que desde ésta pueda ser planteada una exploración hermenéutica; simplemente se advierte como el tránsito a la visibilidad (Sienra, p. 70).

El inicio de siglo, muestra una "tendencia" que lleva a los territorios a la urgencia de contar con un identificador visual distinto a los símbolos instituidos históricamente, a razón de una apremiante necesidad de ser reconocidos en el escenario global. Presiones tanto internas como externas, incitan a mostrar en el contexto mundial, una sumatoria de atributos y factores diferenciales que otorguen valor al territorio a través de la gestión de una marca. Esta funciona como estrategia de venta del territorio en sus múltiples facetas incluso la de las personas que lo habitan. Narra en sus dinámicas, imaginarios y realidades y en este sentido afecta simbólicamente y de manera amplia a quienes la ven, ya sea por ser nativo, inmigrante, ciudadano, extranjero, etc., o por la importancia que cobra saber el origen de las cosas, el made in, para la decisión de compra. Además es una necesidad creciente de posicionamiento en los mercados internacionales en función de obtener un papel significativo en el mundo. El territorio, al igual que una empresa, deberá desempeñar "funciones de producción" (Sassen, 2001).

En el mundo, un gran número de países han promovido su identidad desde finales del siglo pasado y comienzos de éste, ya no desde los productos sino en la perspectiva del marketing actual, que se traduce en “¡Marcas sí, productos no!”: tal fue la divisa del renacimiento del marketing, liderado por la nueva clase de empresas que se consideraban

"Vendedoras de significado" y no como fabricantes de artículos. Lo que estaba cambiando era la idea de lo que se estaba vendiendo, tanto en cuanto a la publicidad como en cuanto a las marcas. El antiguo paradigma era que todo el marketing consiste en la venta de productos. En el nuevo modelo, el producto siempre es secundario respecto al producto real, que es la marca, y la venta de la marca integra un nuevo componente que sólo se puede denominar espiritual. La publicidad es la caza de productos. La construcción de las marcas, en sus personificaciones más auténticas y avanzadas, es la trascendencia de la empresa (Klein, 2013, pp. 48-49).

La marca territorio busca en lo local, la adhesión de las personas seduciéndolas para que se vinculen de nuevo a las políticas del Estado nacional y en el escenario internacional competir a nivel global. En un escenario se es producto, en otro, es cultura (Dinnie, 2008). Pero a pesar de los muchos esfuerzos por la enunciación de discursos positivos a través de la marca país, la negación de los derechos en contraposición a las promesas de bienestar por parte del Estado, ha incentivado en mucho, la desvinculación de los individuos de su sentimiento de pertenencia al mismo. 
Las marcas forman parte del sistema-mundo capitalista que procura todo como mercancía, haciendo del lucro su única finalidad, “(...) es una muestra del patrón de poder dentro del cual habitamos, y el cual además nos habita; del modo como el capital y el capitalismo mundial han estado desarrollándose, en una tendencia cada vez más perversa, cada vez más tecnocrática" (Quijano, 2010, p. 55), y sin embargo, exitosa. Así lo señalan rankings como el registrado por Future Brand ${ }^{7}$, donde se expone el lugar que se está ganando el país en el mundo y en la región gracias al marketing territorial.

Es cierto que la marca como potenciador simbólico conjuga la identidad, el posicionamiento y la imagen de un país desde la perspectiva de las relaciones públicas, pero también genera un reduccionismo del territorio a "producto" en proyección de utilidad, (Echeverri, Estay \& Rosker, 2012), ocasionando una falsa idea de singularización, cuando en realidad homogeniza en lo global, desmantelando, muchas veces, el tejido productivo endógeno que existe, gracias a la colonización económica exógena, lo que fomenta desigualdades económicas, sociales y ambientales. En otras palabras, todo lo contrario a lo que promete. La marca de lugar se proyecta en lo visual, pues esta es su expresión simbólica, se revela a través de un sistema complejo entre texto, contexto e imagen que se soporta en macro estructuras y superestructuras. En suma, a través de una gama de recursos tecnológicos afecta a los individuos de diversas maneras. En este sentido el concepto de identidad se reduce en la marca a la permanencia y persistencia del mejor modelo que pueda ser expuesto. Por esto, la identidad en relación al territorio, según Reyes, (2000), es comparable con la ciudadanía y con la identidad nacional. Con la ciudadanía, pues esta

Implica membresía, pertenencia a un Estado, es decir, a un sistema político e igualdad sin distinciones ante dicho Estado, pero por otro también con la noción de identidad nacional que implica el reconocimiento de lazos comunes que, a su vez, incluyen algún grado de exclusión y segregación. El uno se ubica en el ámbito de la política, el otro en el de la cultura. En situaciones históricas particulares cualquiera de los dos puede crecer en detrimento del otro $y$, por lo tanto, producir diferentes resultados (Zuñiga, 2010, p. 169).

La "marca territorio" está ligada al primer tipo, pero su estrategia se sostiene en el segundo, pues entre sus intenciones están, uniformizar "culturalmente", pero manteniendo la unidad del Estado. Entonces es una marca que comercializa un producto, el territorio. Es asumida como otro emblema nacional y es soporte de relaciones internacionales, lo que evidencia aún más su base política y su carácter de manipulador simbólico (Bourdieu, 2010, p. 169).

Por ejemplo, entre los objetivos planteados en el desarrollo de la marca "Colombia es pasión" referenciados por Moreno y Figueroa, (2010), estaban: "generar una sola identidad que integre todas las actividades productivas del país y promocionar y posicionar una identidad clara, definida y unificada y evitar los regionalismos" y entre los resultados obtenidos aparecen los siguientes: "Mejora la imagen de un país; alinea la percepción de los ciudadanos hacia un mayor patriotismo y orgullo nacional; ofrece una ventaja competitiva a medida que los países compiten en tres indicadores específicamente: inversión, turismo y exportaciones; refuerza el concepto made in en las etiquetas de los productos 
que se comercializan en mercados internacionales". Ahora bien, la pregunta por la identidad, el plano histórico de su construcción; no parece ser relevante, a menos que de ella dependa su valor de intercambio.

Dos de las tendencias vigentes en las discusiones sobre la identidad (Hall, 2010), corroboran lo dicho: la primera, la idea del mundo globalizado que propende por una progresiva unificación planetaria que otorga a lo local un lugar dentro de sus dinámicas. Y la segunda que remite a la emergencia de nuevas y plurales identidades que se advierten gracias a procesos de etnogénesis o de empoderamiento y reconocimiento social, político o económico. En el primer marco, se considera la marca visual de lugar como parte del discurso hegemónico que desde su simbolismo reúne las condiciones de procedencia, diferencia, pertenencia, temporalidad y espacialidad, que remiten tanto al lugar como a los individuos que lo habitan. Se ubican dentro de las representaciones sociales del poder moderno, (Abric, 2001; Moscovici, 1984; Jodelet, 1986), que ha pasado a manos diferentes de las de los Estados nacionales. Según Doise (1992), éstas se constituyen en principios generativos de tomas de postura que están ligados a inserciones específicas en un conjunto de relaciones sociales y que organizan los procesos simbólicos implicados en esas relaciones.

En efecto, los Estados nacionales periféricos y semiperiféricos históricamente se han venido erosionando en el plano nacional, en sus interacciones y confrontaciones con fuerzas subestatales y en el plano internacional, con los Estados Centrales y con otras fuerzas supraestatales. Según de Souza, lo nuevo es que este debilitamiento de la soberanía sucede también a nivel global, a los Estados poderosos (De Souza, 1995, p. 413).

Los efectos de este proceso, concluyen con el surgimiento de identidades emergentes, que definen otro tipo de noción sobre el mismo concepto de comunidad, pues lo separan de su relación con el Estado nacional, rechazando elementos coercitivos con la libertad de seguir intereses propios (Ibáñez Angulo, 2008, Vicente A. y Moreno MT.). Estos se enmarcan en el segundo modelo del que habla Hall, 2010, el de la emergencia de "resistencias". Son identidades que propenden por hacerse un nicho visible en el orden mundial traspasando las fronteras nacionales, en una dinámica no muy diferente a las que logran prácticas y bienes que originalmente eran locales, re-localizándose en otros lugares del planeta instituyendo nexos locales donde antes no existían.

Son alternativas diferentes a los marcos sociales que pretenden limitarlas, expresan de otras formas lo local y cargan de significado la identidad de origen. Son micro-resistencias locales, alteridades vitales al margen del pluralismo global. También llamadas identidades colectivas de vecindad, que vinculan a los individuos a territorios físicos o simbólicos y a temporalidades compartidas pasadas, presentes o futuras (De Sousa, 1995, p. 414). Propenden por el reconocimiento de las identidades asociadas a la raza, al género, a la orientación sexual, a la clase socioeconómica, a la religión, a la edad, incluso a las habilidades. Muchas veces en la misma dinámica de la representación desde el poder, terminan radicalizando sus perfiles y homogeneizando lo diverso. La consecuencia social de esta acción redunda en falsas impresiones, imaginarios y prácticas diferentes a sus principios y necesidades y cierran el círculo de desconocimiento en el que históricamente los ha mantenido el Estado.

La identidad visual de estas resistencias, al igual que la marca lugar representan estéticamente lo que son y de esta manera se convierten en objeto de estudio, pues su interre- 
lación con la identidad es obligada. En la perspectiva del arte, según el Maestro Freddy Ojeda Jayariyu: las manifestaciones artísticas han sido el medio que posibilita a todas las culturas originarias, subsistir y pervivir en medio de la aculturación al mismo tiempo que promocionar su propia identidad ${ }^{8}$. Por otra parte se destacan propuestas como la de Bourriaud, 2006, que describe la experiencia artística como un punto de inflexión para que la cultura local se revalore en un proceso compensatorio frente a la globalización. El arte debe instalarse en el intersticio social, para lo cual propone la presencia del factor relacional en la práctica artística como una imperiosa necesidad de animar la recuperación y reconstrucción de los lazos sociales a través del arte. En Colombia, en particular, en procesos de "reparación simbólica", el arte ha sido protagonista, aunque muchas veces su expresión no ha tenido éxito por ser impuesta desde el exterior en contextos donde la reparación solo es posible desde el interior de las comunidades.

\section{Algunos antecedentes}

Entre acciones y prácticas de imaginarios y representaciones visuales, están diferentes ejercicios académicos y profesionales e investigaciones de alto impacto que se acercan a la visualización, interpretación o muestra de identidades sociales.

Imaginarios Urbanos. Liderado por Armando Silva ${ }^{9}$, se constituye en el mejor referente de la relación imagen, imaginarios y representaciones de identidad actualmente. Enuncia los mapas afectivos que constituyen la diversidad de modos de ser urbanos en varias ciudades de Latinoamérica. No se piensa en una identidad latinoamericana, sino en las mil y una formas de ser en nuestras ciudades, ya no son solo entendidas como un pedazo de tierra, sino como un corazón palpitante, un espacio simbólico de encuentros y desencuentros, un calidoscopio de percepciones y deseos en constante transformación. Silva, entiende el concepto de identidad más como un proceso que como un estado. "O sea, vamos siendo; no somos algo definitivo y estático". Las identidades se desmaterializan, se desterritorializan y los ciudadanos se identifican con quienes están conectados. "Los imaginarios urbanos no están en un pedazo de tierra, sino es lo que anima a una representación grupal”. Sentirse parte de, en este proyecto se explica como un deseo. Luego una experiencia compartida y al final un acuerdo colectivo. Este proyecto se ha desarrollado en más de 25 ciudades de Hispanoamérica, Europa y USA, financiado por el Convenio Andrés Bello, además de otras muchas entidades culturales en varios países.

Estudios sobre semiótica de la marca. Andrea Semprini, (1995) docente de la Universidad Lumiere Lyon 2, especialista en marca con enfoque sociológico y semiótico, ha desarrollado su investigación entendiendo la marca en la posmodernidad y profundizando en temas semióticos.

Marca país CO. En Colombia, resulta un antecedente importante, la marca territorio como estrategia que se viene implementando desde el Estado y ha cobrado fuerza desde hace algunos años. Su cobertura es posible gracias a la descentralización, que en un marco 
legislativo le ha traspasado el poder económico a los municipios o territorios consolidados. Bogotá, Medellín, Ibagué, Cartagena, Ipiales, entre otros, han entrado en su dinámica para potenciar sus planes de gestión a partir de una marca. La estrategia inicia en la mayoría de los casos por un concurso, como el recientemente abierto para marca región "Soy Boyacá", y continúa con un plan de gestión. También es cierto que muchos de nuestros territorios se encuentran en cierto estado de fragilidad ocasionada por varios factores, entre estos, la corrupción, la migración, el desempleo, el ingreso de tecnologías de forma irregular, etc. Implementar estrategias de marketing territorial e incentivar actividades económicas parece, a primera vista, "garantía" de preservación de lo local y desarrollo sostenible.

Marca país del Área. El desarrollo de marca en países como Perú, Bolivia, Ecuador, Chile, Paraguay, Uruguay, Brasil y Venezuela, responden a estrategias estatales que se muestran como incentivadoras del turismo, pero que en el fondo se soportan en objetivos políticos y económicos, cuya finalidad reside en la asociación polos de deseo y la vinculación de los locales para lograr mayor cohesión nacional, al mismo tiempo que una mayor gestión territorial a nivel global en el marco de planes estratégicos como el Consenso de Washington, o el plan 2020 UE.

Consultores de marca. 1) Un compendio de estudios realizados por el DIRCOM ${ }^{10}$ sobre las marcas en Latinoamérica presenta varios puntos de vista sobre sus alcances. Uno en particular, "El hombre y sus marcas", Sánchez, E. (2005), da cuenta desde la antropología de la marca como Tótem insignia para la construcción de realidad de una comunidad. Para elaborar esta idea, se centra en un contexto globalizado y un análisis de mentalidades, para concluir que la marca opera como un sistema global de narración de identidad. Este estudio se propone y se realiza en el marco del Proyecto Estrategia Marca País Argentina. 2) Para Simon Anholt, el mundo es un mercado. El rápido avance de la globalización implica que todos los países, todas las ciudades y todas las regiones deben competir entre sí por ganar consumidores, turistas, inversionistas, estudiantes, empresarios, eventos deportivos y culturales internacionales, y por la atención y el respeto de su comunidad, de los medios de comunicación internacionales y de otros gobiernos. Sus investigaciones se remiten a corroborar el éxito de estas marcas en el mundo y a ofrecer estrategias de intervención desde esta experiencia. 3) Gover y Frank Go, ofrecen ideas sobre el pasado y el futuro de la práctica del place branding. Para ellos la marca es una construcción que conecta la identidad con la imagen y consciencia percibidas. La marca territorio se trata de estrategias que apuntan a construir un valor de marca para los lugares mediante la promoción de un adecuado conocimiento de los mismos así como de asociaciones de imagen positivas. Su propuesta de investigación se centra en el caso de la aplicación de estrategias de marca y de marketing al desarrollo económico, social, político y cultural de ciudades, pueblos y regiones alrededor del mundo para ayudarlos a competir en mercados globales, nacionales y locales.

\section{Prácticas emergentes de creación de identidad visual}

Colombia - Popular de lujo. Por más de 15 años, este colectivo se ha dedicado a investigar la cultura visual y la gráfica popular en Colombia, imágenes que se producen al margen de 
los grandes medios de comunicación y por fuera del circuito de las agencias de publicidad. "Al revisar la gráfica popular con respeto, estamos señalando el valor de una valiosa cultura visual largamente subestimada y contribuyendo a dar mayor visibilidad a personas, comunidades, experiencias y costumbres que no han tenido suficiente representación en América Latina". http://www.populardelujo.com

En Bogotá, igual que en otra ciudades del país, surgen diferentes colectivos locales que en su prácticas, por lo general desde el cine, el comic o el arte, construyen identidad desde la resistencia, La Tremenda Revoltosa batucada feminista, Ántrax Street Art, Festival ojo al sancocho, Sharpball, etc, y colectivos globales que se fijan en lo local como el colectivo Hijos que aparece en varios países del mundo pero que tiene su expresión en lo local. Por otra parte gran parte de las acciones de estos colectivos tienen su iniciativa en los jóvenes y se dirigen a ellos, abriendo las posibilidades al reconocimiento y afirmación identitaria posible de ser expresada en las ciudadanía comunicativa, concepto acuñado por Germán Muñoz (2006, Clacso).

Por otra parte se dan en Colombia fuertes movimientos sociales que desde la estética buscan recuperar su identidad después de más de 50 años de violencia a través de la reparación simbólica por fuera del marco institucional, como son las Tejedoras de Mampuján - Corregimiento de María La Baja (Bolívar) uno de los municipios de los Montes de María que hace 17 años sufrió la campaña de terror de los paramilitares.

Argentina - Colectivo Iconoclasistas. Es un colectivo que desde el año 2006 combina arte gráfico, talleres creativos y la investigación colectiva a fin de producir recursos de libre circulación, apropiación y uso, para potenciar la comunicación, tejer redes de solidaridad y afinidad e impulsar prácticas colaborativas de resistencia y transformación. Su práctica se extiende por y mediante una red dinámica de afinidad y solidaridad construida a partir de compartir e impulsar proyectos libres y talleres colectivos por Argentina, Latinoamérica y Europa.iconoclasistas@gmail.com; Colectivo Onaire. Colectivo gráfico formado por diseñadores gráficos argentinos egresados UBA, que desarrollan un método de trabajo propio. Trabajan temas relacionados con la historia, con la realidad social y cultural. Elegido el tema tienen una primera etapa de expresión individual, donde cada uno vuelca su mirada, sus pensamientos y dibuja. Luego los recortan y hacen un gran "guiso gráfico". Una pieza en común donde se unen las visiones de cada uno en una sola composición. Se rompe la expresión individual para lograr una expresión colectiva. El grupo cree que el diseño y su capacidad de expresión pueden fomentar el conocimiento y hablar de la sociedad a través de un lenguaje que los representa, múltiple y heterogéneo. El Siluetazo. La realización de siluetas como práctica artístico política se presentó en los años 80s en Argentina como una práctica de reivindicación en la que se representaban "la presencia de una ausencia", la de los miles de desaparecidos durante la dictadura militar.

Ecuador - Mingasocial. www.mingasocial.net. Es un espacio de comunicación alternativa que interactúa con la comunidad. La comunicación permite activar la conexión, el encuentro y la juntura social provocando la emancipación constante de los sujetos dentro de las sociedades. Su objetivo es contribuir con instrumentos de discusión y reflexión que aportan a crear y fortalecer procesos sociales, culturales y políticos que idealizan una 
comunidad social equitativa, democrática y más humana. La Minga, es uno de los ejes de asociación indígena y popular más reconocidos en Latinoamérica.

Chile - Chilogo. Surgió durante 2008 como un ejercicio académico en los talleres de segundo año de la carrera de Diseño Gráfico de la U. del Pacífico en Santiago de Chile. Allí los estudiantes, junto a sus Profesores Pedro Álvarez y Cecilia Durán, abordaron el tema de la identidad nacional a través de la creación de pictogramas del Chile de antaño y también el de hoy. El proyecto original buscó -tomando como referencia los trabajos de Otl Aicher, Lingua Gráfica y Lingua Universalis (de Mutabor, Alemania), Nobrand (del estudio imagenHB, Argentina) y algunos antecedentes locales como Tipicons, Dingbats República (Pablo Rivas) y Chilepixel- rescatar ciertos personajes, eventos, tradiciones y rasgos que son propios del imaginario cultural chileno, resultando una particular galería donde toda la carne se puso a la parrilla: desde los mitos mapuches, a un fragmento de cordillera, un prócer nacional o algún sobreexpuesto animador de televisión, los íconos desfilan como hojas de ruta que describen con la simplicidad de algunos trazos un país lleno de fortalezas y también debilidades. https://www.chilogo.cl/

\section{La representación visual de identidad}

La marca visual es una construcción estética que narra lo que se es como entidad diferenciada en una imagen, reduciendo parámetros complejos de identidad a necesidades puntuales de reconocimiento. Esta imagen visual que en principio se presenta como emblemática, en la gestión se llena de significados para convertirse en un símbolo. Representa sistemas ideológicos, políticos, sociales, culturales. No parece cuestionable, pues es lo que es, gracias a la estratificación del poder y a las presiones económicas que fomentan su aparición y sustentan su validez. Si es dominante, su base son ambiciosos estudios de marketing, además de mediciones de impacto económico y diplomático. Si es emergente, su base son las adhesiones, las lealtades y las redes.

Es también fenómeno de comunicación y como tal es producto de una institucionalidad que quiere transmitir ciertos contenidos de su identidad a una pluralidad de receptores de forma homogénea con el fin de obtener algún tipo de beneficio en algunos casos de carácter económico; en otros la búsqueda de la visibilidad con algún interés.

Para el Diseño de Identidad Visual, campo profesional especializado en diseñar símbolos, signos y logotipos; una entidad es un sujeto que puede ser público o privado, individual o colectivo, incluso, puede ser perdurable o efímero. Se diseñan identificadores visuales, que se convertirán en marcas a diferentes sujetos: empresas, productos, sujetos, etc. Un territorio, país, ciudad, reserva; es uno de los sujetos más complejos que existen. En este marco, una de las críticas constantes al diseño es la cosificación de la identidad, pues la identidad volcada en la marca, ha sido propicia al sistema capitalista que poco a poco y con ayuda de los creadores de imagen, ha venido reduciendo su valor simbólico y sus referentes culturales producto de la historia, al mínimo necesario para beneficio del intercambio comercial. Esto muy a pesar de la reflexión de varios teóricos en la perspectiva de diseño social, cu- 
yas posturas resultan críticas ante estos efectos (Frascara, 1997; Papanek, 1977; Margolin, 2012-2015; Ochoa, 2012).

Para Costa (2003) "la Marca territorio es un nuevo fenómeno de la cultura global de servicios. Es una macromarca y como tal debe ser concebida y gestionada. Es una realidad multipolar. Una constelación irresistible de macro y micro polos de deseo". Es un entramado simbólico entre comunicación y sistema visual que se convierte en paraguas que cobija todo lo que el territorio es, hace y proyecta. (Chaves, 2001; Costa, 2003; González Solas, 2004; Ollins, 2002).

La ampliación del concepto a una dimensión geopolítica, además de los discursos afines al diseño, cubre la premisa sociológica, el marketing territorial, el posicionamiento, la economía y la reputación. Esta última entendida como un proceso mediante el cual la imagen de una nación puede ser creada, monitoreada, evaluada y gestionada con el fin de mejorar o aumentar la reputación de un país en la opinión pública de una audiencia internacional, evitando la imposición de la misma (Anholt, 2007; Fan, 2009; Boiser, 2006), por lo que se recurre a un trabajo focalizado sobre la base del poder blando con lo que se establecen relaciones de confianza (Van Ham, 2005). El Soft Power (Anholt, 2007; Azpiroz, 2012), en el marco del marketing territorial es una de las estrategias de la Diplomacia Pública ${ }^{11}$, Jian Wang (2011) y Melissen (2005) señalan que los valores de un país -democracia, derechos humanos, comportamiento de sus líderes- son indicadores para concentrar poder blando en un entorno diplomático.

Los conceptos de country brand, city branding y place brand, con los que se nombra la marca territorio, provienen de varios autores: Olins (2002); Govers (2009); Anholt (2008); Gobe (2010); Echeverri Rosker (2014), entre otros. Específicamente en nuestra región "Marca País", fue propuesto por primera vez por el argentino Roberto Occhipinti, en "Conciencia Exportadora (1989)" ampliándolo en "Marca País" (2003). El posicionamiento de "marca país" en el mundo ya se venía gestando desde finales de la II guerra mundial con la conversión industrial de grandes empresas a multinacionales que se expandieron al diseminar sus productos por todo el mundo, de forma muchas veces asistencialista. Este primer reconocimiento de marca se hizo bajo la noción de "productos de origen", por ejemplo Estados Unidos con Olivetti, IBM o Coca-Cola, o Colombia con Café de Colombia. Para esa época el escenario mundial ya contaba con símbolos que aún hoy continúan marcando a los lugares. Es el caso de la Torre Eiffel, las pirámides de Egipto, El Taj Mahal, las cataratas del Niágara, etc.

En el proceso de significación, la marca de un país es atravesada por imaginarios de identidad nacional. En el caso colombiano, lo autóctono, lo precolombino, lo popular, los narcos que se vuelven superhéroes, las reinas y su belleza, la pobreza y la riqueza natural; en tránsito de lo que debería ser, a finalmente lo que es (Castoriadis, 1986). La postura de Bourdieu en este aspecto es muy significativa y está en coherencia con lo citado por Silva en relación a lo público, al individuo y a lo colectivo pues para él, siguiendo a Michel Foucault,

Las técnicas de gobierno incluyen no sólo las del gobierno de los otros sino las del gobierno de sí mismo, de esta manera lo que se entiende por "sí mismo", estaría determinado por una modalidad de gobierno, sería el producto de un conjunto de prácticas de poder que constituyen una subjetividad y dirigen su 
conducta. (...) Así por un efecto que caracteriza apropiadamente las relaciones de (des)conocimiento y de reconocimiento, los detentadores de la identidad dominada aceptan, la mayor parte del tiempo tácitamente, a veces explícitamente, los principios de identificación, de los que es producto su identidad (Bourdieu, 2006, p. 167).

La marca en su doble dimensión estética y política, entra a interactuar dentro de algunos de los parámetros que explican lo público hoy en día, según Silva, (2013), "lo público se revela como la instancia para arrojar proyectos colectivos (...) desde la cual, se plantean acciones de promesas de un nuevo mundo, una nueva vida para individuos y sociedades, justo mediante la estrategia de impactar públicamente". Para reiterar lo dicho, Silva también toca el punto en el que expresa que las manifestaciones estéticas, el arte público por ejemplo, $-\mathrm{y}$ adiciono yo, los diseños de marca-, son:

Manifestaciones, concebidas así sea de modo contradictorio, se traducen en "modos de ser públicamente", y permiten entrever los órdenes de las representaciones colectivas como instancias fraguadas por los imaginarios: unos de afirmación grupal convenida, otros de irrupción contra lo establecido. Es esa su naturaleza ético-estética (Silva, 2013, pp. 25 y 27).

La marca territorio es también un tipo de representación de la identidad nacional, al ser producto y proceso, expresa la organización de significados comunes a un grupo humano. En pocas palabras, la noción de marca no se refiere únicamente al identificador visual, sino también a la imagen pública y a la reputación del sujeto, en este caso un territorio habitado, o una suerte de territorialidad. La marca lugar deja de lado la bandera y el escudo que históricamente fungían como estandartes de la identidad nacional: ideales, valores y límites geográficos. Es ahora la marca la que suple esta función, no obstante lo hace desde su condición de dispositivo (Agamben, 2015) propio del mundo capitalista. En la actualidad, las marcas territorio son una referencia directa al espacio geopolítico de la nación. La marca así asumida, representa desde una postura política y abiertamente pública, la identidad dominante, que procura que otras identidades se subordinen a ella o se asimilen a través de imposiciones veladas que son adoptados por los dominados gracias a formas simbólicas de presión representadas por la agencia de la imagen símbolo y sus sistemas en las percepciones del sujeto individual tanto como del sujeto colectivo.

Los Estados nacionales buscan recuperar el poder perdido y fortalecer su imagen y el soft power, parece ser uno de los caminos a seguir por ser una estrategia para estandarizar social y funcionalmente a los ciudadanos con el fin de fortalecer los vínculos que los mantienen unidos al Estado para establecer una suerte de continuidad y cohesión al interior del mismo (Hobssbaum, 1993). También funciona según Joseph Nye (2004), por darles la capacidad, como actores en el sistema internacional, de obtener lo que quieran a través del atractivo de su cultura sin la necesidad de ejercer una influencia militar o económica para lograr el mismo fin.

En el contexto diplomático y económico, la marca fija la identidad. Su efectividad en el mercado, demuestra que homogeniza lo imposible de homogenizar, reconoce la diversi- 
dad en dinámicas económicas, mientras que en el factor humano, la heterogeneidad se encuentra en la estigmatización de la diferencia, que hace visible al otro mostrando su debilidad, como una señal y ocultando tras un positivismo insulso, como en el caso de Colombia, la historia de violencia. La idea de estigma surge en relación directa con la capacidad para narrarse a sí mismo desde lo negativo por la idea equivocada de estar siendo narrado oficialmente como reivindicación de sí. "El mundo social es también representación y voluntad, y existir socialmente consiste en ser percibido y percibido como distinto" (Bourdieu, 2009, p. 173). Con ello se podría explicar el éxito que tiene esta estrategia a nivel internacional.

En este sentido, la globalización toma su papel en el discurso de la identidad, imponiendo el mundo de la marca. Se lanza un discurso que muestra solo las facetas más adecuadas ante las imposiciones internacionales recomendadas a los países latinoamericanos para reconocerse como unidad territorial competente, atraer capitales privados e incorporarse al sistema internacional. Implantan formas de verse y de asumirse a partir de un ideal útil al mercado, afectando de manera indirecta la identidad nacional y los imaginarios de nación. Lo logran con diferentes formatos de inserción simbólica que desmaterializan la realidad. Crean una dimensión alterna en la que existe un territorio físico y una identidad ligada a él que se dice de "unidad nacional" y de esta manera, evidencian el abismo que hay entre lo que narran y las realidades endógenas del lugar.

No se puede desconocer la necesidad de los países de entrar al escenario mundial, es sumergirse en interconexiones globales en tiempo real y generar una nueva territorialidad hecha de hibridaciones locales, nacionales, regionales, estatales, interestatales, paraestatales y supraestatales, necesarias para el desarrollo de cada país, entendiendo que al hacerlo, se somete a un ejercicio del poder dominante a través de dinámicas en las que las articulaciones ya no son con el estado, con el ente de poder al frente de éste, sino con el mundo en sentido unitario, es decir se crea un estado de hiperrrealidad, donde el capitalismo se simula como una verdad objetiva sin lugar a controversias, como bien lo enuncia Henao y Rodríguez (2006, p. 83), citando a Baudrillard.

En síntesis, no puede ignorarse que finalizando el siglo XX y en los inicios del siglo XXI, estamos ante una proliferación de identidades en el espacio social que se someten a las políticas sincrónicas de las prácticas de la representación como obra del poder, en las que se supone a un individuo, actor social que encarna la totalidad. Su consolidación se da por la desaparición del objeto concreto, del que permanece algo para que exista una correspondencia y son pensamiento constituido y pensamiento constituyente que sirven para interpretar la realidad, son producto y proceso, por lo tanto sirven para reconocer el tipo de sociedad en la que han surgido (Ibañez, 1988, Balandier, 1992).

\section{Relación representación-identidad}

La identidad social es un criterio de difícil definición. Está constituido por el espacio social, el discurso de la etnicidad, la territorialización, la diferencia y está atravesado por la cultura. Su interpretación deviene en mucho de las representaciones que de ella se hagan y de los imaginarios que surgen de estas. En general pueden propender o no, por la homogeneidad o por la diferencia. En este sentido y en acuerdo con Silva (2013), se entiende que 
en lo global, están los discursos estandarizados de la identidad; mientras que en lo público, lo diverso, lo dinámico y por ende, la emergencia de las resistencias.

Homi Bhabha (1995), afirma el dinamismo y pluralidad de las identidades sociales: la resistencia del sujeto colonizado emerge, necesariamente, al margen de las identidades fijas o en su momento catacrético:

Las complejas estrategias de identificación cultural y discursiva apuntan a que la función en el nombre del 'pueblo' o 'la nación' son más híbridas en la articulación de diferencias culturales e identificaciones - género, raza, clase que lo que puede ser representado en cualquier estructuración jerárquica o binaria del antagonismo social (Citado por Jhon Beverly, 1990, p. 292).

Para otros autores, la identidad está directamente relacionada con la nacionalidad (Reyes, 2008, Mercado \& Hernández, 2010), se entiende a la nacionalidad como forma comunitaria de vínculo entre individuos y se le otorga la idea de memoria colectiva, de construir un todo, un territorio, un futuro juntos. "De esta manera podríamos muy brevemente decir que esta doble construcción, la de la etnia y la de la nación, comportan dos miradas en direcciones distintas pero complementarias: la etnia mira al pasado y la nación al futuro" (Reyes, 2008, p. 168).

Adicionalmente hay dos afectaciones a esta idea que no pueden desconocerse, la primera es que se asume que todos los ciudadanos pertenecen a la misma comunidad o "nación"; y la segunda es que, como se enunció anteriormente, lo que une a estos individuos es una etnicidad, lengua, raza, religión o antepasados comunes (Castells, 1997-1998). Ante esto Hobsbawm aclara que la "cohesión comunitaria de los ciudadanos en la nación política no implica ninguna otra forma de homogeneidad, excepto por motivos pragmáticos" (Hobssbawn, 1993, p. 7).

La definición de la identidad antes centrada en la unidad de instituciones tradicionales: el Estado, la Iglesia y la Escuela, ahora se define por otras formas de pertenencia y de unidad, atadas a los nuevos medios de interacción digital. Que aunque parecen más leves y frágiles, garantizan la solidez del grupo a partir de estrategias diferentes a las establecidas tradicionalmente.

Según Hobsbawm,

No hay límites para el número de formas en que yo podría describirme a mí mismo -todas ellas simultáneamente ciertas, como bien saben quienes confeccionan los censos-. Puedo describirme de cien formas distintas; y según cuál sea mi propósito elegiré resaltar una identificación sobre otras, sin que ello suponga en ningún momento excluir a las demás (Hobsbawm, 1993, p. 5).

Las identidades sociales se inscriben tanto en lo individual como en lo colectivo y se movilizan en lo simbólico y en lo cultural construyendo y deconstruyendo procesos identitarios en un territorio que se vuelve propio o que se desterritorializa por infinidad de razones (Motta, 2014, Nancy, 2006, 2007) ${ }^{12}$. En esta idea, Hall (2003), afirma que las identidades son construcciones sociales, y como tales las distingue histórica y estratégicamente en dos 
modelos: las singulares con cierto contenido intrínseco y esencial definido por un origen común y una estructura común de experiencias, y las múltiples, temporales, inestables, relacionales e incompletas, siempre en proceso. Ambas conviven en la misma temporalidad y responden a estrategias similares, además, los sujetos que las protagonizan pueden estar situados en la estructura de poder o al margen de esta.

\section{Imagen, visibilidad agente}

Los estudios visuales se han propuesto replantear los términos de la investigación acerca de la imagen, ya no como dominio exclusivo del arte, la estética o la historia del arte, sino desde un ámbito que la conciba como un fenómeno expandido y presente en múltiples instancias que conforman nuestro habitar (Sienra, et al. p. 16).

Por ellos es necesario pensar la imagen desde los Estudios Visuales que en el marco de los Estudios Culturales han ampliado la discusión con relación a la imagen y a la representación desde categorías como la visión, la mirada, la visualidad y el discurso, en directa consecuencia con los medios técnicos y tecnológicos que la hacen posible en contextos sociales (Renaud, 1999; Nancy, 2007-2008; Didi-Huberman, 2008).

En este sentido W.J.T. Mitchell, en 1992 en el "El giro Pictórico" o "giro icónico", consideraba que la imagen sustituye al lenguaje como centro de conocimiento y moldeador de conductas sociales. Buscaba comprender los mecanismos de sentido de las imágenes y ver a la imagen como un elemento idóneo de estudio de lo cultural, para rastrear las intersecciones de la representación, el lenguaje, la historia, la imaginación, etc. De lo que se trata no es de disputar hegemonías sino de analizar la visión en relación directa con las prácticas culturales específicas (Mitchell, 2003; Ledesma, 2010).

Entender que la imagen es inferencia social (Arfuch, 2006) amplía los análisis sobre la misma más allá de los estudios sobre óptica y percepción y los lleva al contexto social, político y económico. Brea (2005) y González Requena (1988), en la misma línea, reiteran la posibilidad de encontrar conocimiento sin articulación discursiva, (González Requena, 1988). La idea del panóptico de Foucault, y del Gran Hermano de Orson Welles, (Guigou, 2001), sigue cobrando sentido en la medida en que se sigue reproduciendo mecanismos de poder totalizantes para vigilar (Sienra, 2014).

La visualidad y la visibilidad surgen como elementos indispensables para la profundización social: "Visualidad como la estrategia de presentación a partir de la cual se puede hacer comprensible un horizonte de reflexión" (Bourriaud, 1999) es visualidad no en términos de lo que dispone a nuestra mirada sino lo que nos hace posible visualizar (Sierna, 2014). Y visibilidad:

El hecho de que la prioridad sea de la red, y no de los individuos, implica la posibilidad de disimularse en ella, de desaparecer en el espacio impalpable de lo Virtual, y entonces, de no ser ya localizable en ninguna parte, lo cual resuelve 
todos los problemas de la identidad, sin contar los de alteridad (Barbero, 2008, pp. 76-77).

El concepto visibilidad agente permite reconocer los cambios actuales de la mirada con lo que se busca revelar que la imagen representación de identidad, está formada por dos elementos: la imagen que la constituye y la visibilidad que agencia. En el contexto actual mediado por las TICs, la simulación, la realidad virtual, la realidad aumentada; se construyen nuevos vínculos con lo visible, el ser humano entra en dinámicas que a través de la percepción afectan todos los niveles de la vida, ya que las imágenes-representación observadas no son representación de lo real en el orden de lo que se entendía por lo real. Señala Renaud (1990) que "La imagen, objeto óptico de la mirada se convierte en imagerie, praxis operativa de una visibilidad agente". Esta imagen-representación más allá de ser reflejo, es link que posibilita la llegada a otros mundos de conocimiento y a la construcción de redes socioculturales, esto en un contexto que podría ser el de modernidad líquida, Bauman (2004) ó según la interpretación que se asuma, la era del vacío, Lipovetsky (2000), en el que se produce un cambio en las prácticas habituales desequilibrando los soportes culturales establecidos históricamente y que entran en un estado de cambio constante.

Merleau Ponty (1975) propone que para entender lo visible es necesario la validación de "la invisibilidad" como fundamental en la comprensión de lo visto, por lo que:

Toda percepción está subordinada a un horizonte soberano, y por tanto excede a la propia experiencia de lo percibido al presentarse como una abertura a la "cosa misma", su posterior centramiento intraontológico en la "visión" remite a la profundidad secreta e inagotable de todo "visible" que designa como "invisible" (Carbó, 2011).

Tanto Merleau Ponty como Aumont en sus discursos relacionan la percepción, de hecho, es imposible hablar de visibilidad sin remitirnos a la percepción y al sujeto eje de la misma. Aumont curiosamente titula un pequeño capítulo en su libro La Imagen: "El espectador construye la imagen, la imagen construye al espectador" y lo inicia comentando las tradicionales funciones de la imagen propuestas por Gombrich (1983), pero deteniéndose con mayor precisión en la de reconocimiento y en la de rememorización. Básicamente la primera atiende a la identificación de la cosa vista en la imagen y al placer que esto causa y la segunda a la capacidad para ser recordada atendiendo a ciertos códigos que portan saberes específicos. Para hacer evidentes estas dos funciones necesariamente hay que olvidar completamente la noción de mirada inocente ya rebatida hace bastante años por el mismo Gombridge. Curiosamente parecería que Aumont está hablando de signos identificadores, pues básicamente estas funciones los convierten en lo que son.

El enfoque cognitivo de la imagen aclara ciertas funciones del signo de la identidad, pues además de la imagen, su productor entra a interactuar con los modelos de pensamiento del espectador, lo que implica de una u otra manera una enseñanza de ciertos códigos. Los antecedentes de este enfoque alrededor de la imagen, nos vienen desde Arnheim (1985), pero es Bruner (1984), quien demostró la influencia de la cognición y la motivación en la percepción a través de la observación de varias pruebas con niños, con las que pudo 
determinar que "la percepción se asienta pues sobre la formulación de hipótesis y sobre la toma de decisiones, influyendo en ella las necesidades, valores y deseos del sujeto" (Oyarbide, 2004).

La agencia (Bourdieu, 2006; López \& Enrique, 2004), se remite directamente a la capacidad del sujeto para interactuar en libertad. Comprende las estructuras sociales en las que está inmerso y toma decisiones racionales sobre su vida cuyo resultado determina su acción política en el mundo como un actor social. Para Aristóteles (1995), la agencia se refiere a una potencia de/para actuar, remite a lo posible. La posibilidad de ser de muchas maneras. Adjudicarle a la imagen la categoría de agente sugiere pensarla como dispositivo capaz de agenciamiento, tal cual lo describen Deleuze y Guattari, como un acto indirecto de un marco social organizativo.

Finalmente, la visibilidad agente es convergencia, pues se traslada lo que constituye la acción del sujeto a la acción misma de la imagen, es decir de la imagen a la agencia y de la agencia a la acción del sujeto que ejerce un verdadero efecto sobre la realidad que ya no es individual, del sujeto único sino es una posibilidad compartida por todos los sujetos o toda la colectividad que sugiere sentido de pertenencia con el signo de la identidad propuesto. De este modo la agencia de la visibilidad es la mediación misma entre el sujeto social y su representación. Provocar, generar esta agencia, esta dinamización de lo visible implica poder y desemboca en la acción.

\section{Imaginarios y representaciones}

La representación, concepto híbrido de composición polimorfa, integra en sí conceptos de distinta naturaleza, procesos cognitivos, intersecciones sociales, factores afectivos, sistemas de valores, creencias, actitudes, etc. (Ibañez, 1988); permite reconstruir, repensar y rehacer a modo propio y concreto algo (Moscovici, 1992); es distinta al objeto mismo a pesar de que se desarrolla a partir de él.

Según Abric (2001) y Moscovici (1984), las representaciones siempre son sociales, colectivas. "Todas, siempre, explican hechos y justifican interpretaciones, emociones y comportamientos desde un horizonte compartido" (Páez, 1991). Son a la vez producto y proceso de una actividad mental por la que un individuo o un grupo reconstituye la realidad que enfrenta y le atribuye una significación específica. Son construcciones complejas formuladas e interpretadas por sujetos sociales en un espacio tiempo al que pertenecen. Dependen de las constricciones y habilitaciones propias del contexto mediato e inmediato: naturaleza, finalidad, ideología, dinámica social, lugar del individuo en el grupo, etc. Y rigen las acciones de los individuos, pues determinan comportamientos y prácticas. "La significación de una representación social está entrelazada, anclada siempre en significaciones más generales que intervienen en las relaciones simbólicas propias al campo social dado" (Doise, 1992, p. 189).

La categoría imaginarios ha sido desarrollada por Silva (2013) con base en el psicoanálisis (Freud, Lacan, 1966); los estudios sobre cine (Metz, 1979); la filosofía y la sociología (Castoriadis, 1982). El imaginario "se experimenta como una serie de verdades profundas de los seres humanos así estas no correspondan a hechos comprobables empíricamente". "La construcción de los imaginarios no corresponde a una cuestión caprichosa. Obedece 
al seguimiento de reglas, representaciones, formaciones discursivas y sociales profundas, de honda manifestación cultural”. La relación de los imaginarios con los juegos simbólicos significa "que el ver está reglamentado socialmente, que no vemos con los ojos propiamente, que los imaginarios nutren las visiones, y por ello las operaciones visuales y cognitivas de la ciudad operan bajo formas recónditas que afectan su percepción”. A partir de estas premisas, Silva propone que un estudio de los imaginarios debe recorrer tres registros: la marca psíquica, la construcción social de la realidad, y el modo que permite la expresión material por alguna técnica. En este sentido y atendiendo a sus postulados cabría preguntarse ¿qué significa pertenecer a un país, cuál es el sentido de reconocerse en lo visible de una Marca País, cuando la identidad precisamente puede encontrarse en lo invisible?

Es el paso de la identidad en estado fijo, consolidado y por tanto acabado, a una identidad dinámica

Como expresión societal de un proceso que incorpora relaciones sociales activas; o sea, como la representación que los actores sociales imaginan, elaboran, construyen acerca de sí mismos y de los demás en una fase o momento particular de su existencia. La identidad se aprecia entonces como la auto/representación generada por los actores sociales en el tiempo y en el mundo de vida que los engloba (Aceves, 2001, p. 12).

O como lo enuncia Armando Silva, (2014), un "vamos siendo".

\section{Conclusiones}

La construcción de lo que somos, usualmente responde a nociones de identidad importadas, formadas en otros contextos y la mayoría de estas nociones no son asimiladas, o no lo hacen adecuadamente, por lo que su interpretación sucumbe a estereotipos.

La condición de ser dominador o dependiente deviene en gran parte de la lectura de su representación en un marco político. El papel de los nuevos medios y las tecnologías de la información y la comunicación tienen un papel preponderante en esta lectura, pues suponen estrategias indirectas, amables y exentas de conflicto, por lo que los mensajes emitidos fluyen con facilidad, consolidando imágenes y mensajes relevantes para el mantenimiento del sistema y la construcción de la imagen del país que se quiere fijar en el imaginario social. La representación de lo que somos está en la historia de la nación, del territorio, de los conflictos característicos y emblemáticos propios y del registro sensible de esas complejidades, sin embargo en el diseño de estrategias de visibilización mediadas por la imagen visual, estas parecen ser ocultadas o anuladas.

La agenda global incita al olvido del marco histórico propio y emblemático de cada sociedad e invita al sistema dominante local a dar verosimilitud a nuevas identidades. Estas dinámicas inciden en la producción de representaciones de nuevas identidades transnacionales que responden a perspectivas e intereses políticos de los países centrales, más que a problemáticas de orden local. Las nuevas identidades políticas transnacionales transportan una normativa global que se vuelve predominante, por lo que terminan sobresaliendo, 
incluso substituyendo a las formas tradicionales de alteridad con sus culturas asociadas. La globalización reduce las formas de ser diversos.

La imagen representación de la identidad es una tarea intelectual controlada por unos códigos, parámetros y esquemas culturales dominantes que obedecen a una política determinada que puede ser identificada. Esta imagen es parte y agente del proceso cultural, político y económico de una sociedad.

Entonces, la marca Colombia actual presenta una imagen del país fragmentada, contradictoria y medianamente representativa. Esta y otras formas visuales de representar el país desde la institucionalidad parecen ser el resultado de estrategias políticas y económicas que responden a intereses particulares. Ante este panorama la hipótesis o supuesto, es que el país está sometido a imposiciones de identidad que redundan en una falsa idea de lo que somos encontrándose desmarcado, sin embargo no se desconoce la existencia de dinámicas de reconocimiento, resistencias y proyecciones de reconstrucción social surgidas en el marco de lo local desde las que se proyecta otra imagen del país más coherente. Ambas formas de representar la identidad son susceptibles de ser analizadas, jerarquizadas, escaladas y potenciadas en el marco de los estudios sociales para contribuir a la identificación y categorización de la diversidad de posturas desde las que socialmente se reconoce y se da credibilidad a una identidad local y a la identidad del país, determinar el impacto de la imagen visual material en los imaginarios y la representación identitaria y aportar a la reflexión sobre la agencia de la imagen en contextos sociales.

\section{Notas}

1. Se refiere a la "imagen material visual", que desde el enfoque semiótico de la imagen visual corresponde a entender unas propuestas de percepción visual consideradas como representación (qualia, contornos de oclusión, ejes, marcas), destinadas a la configuración de una forma, para su valoración por el perceptor, para hacer posible su identificación, reconocimiento e interpretación en interrelación con semiosis sociales (Juan Magariños de Morentin, 2001).

2. La categoría agencia se refiere a la capacidad del sujeto para interactuar en libertad, comprende las estructuras sociales en las que está inmerso y desde las que toma decisiones racionales sobre su vida cuyo resultado determina su acción política en el mundo como un actor social, también implica la potencia de/para actuar (Ver Bordieu, 1987 y Aristóteles acerca de la potencia y el acto). Se otorga a la imagen la categoría de sujeto en relación directa a su capacidad para transmitir significados en una semiótica diferente a la semiótica del texto.

3. Ser colombiano, ser parte esencial del país y ser coherente con ello en términos de participación, potenciación del territorio, transformación y percepción de futuro. Sentirse incluido, tener conciencia de pertenencia. Formas identitarias que corresponden con la colombianidad, noción que parece constituirse más en un acto de fe como se enuncia en el cuento de Borges, que en una consecuencia íntima entre el ser y la historia que alimenta esta conciencia (Oscar Collazos, 12/11/1980), en Revista Semana.

4. Semióticas visuales: plástica, figurativa y conceptual (Juan Magariños de Morentin, 2001). 
5. Se presumen diferentes acercamientos a las identidades y a su formación desde los condicionamientos y procesos mediante los cuales los sujetos y los grupos crean el "yo", el "Nosotros" y "el ellos" que partes de visiones hegemónicas, de resistencias o simplemente de: 1) La marca país Colombia y algunas marcas "made in"; 2) Las narrativas mediáticas que proponen nexos entre narración, comunicación e identidad: las novelas, series, bloggers, esferas públicas periféricas (Sola Morales, 2013). Hacia una tipología de narrativas mediáticas identitarias. Sphera Pública, (2), 13, 30-48.; 3) Arte, diseño, comunicación, reparación simbólica justicia transicional: hacer memoria, recuperar la esperanza o defender los intereses comunes. El arte como mecanismo de apoyo para la justicia transicional en Colombia y la recuperación de la identidad; y 4. Patrimonio e identidad cultural: que se identifican en las relaciones que existen entre mercado, consumo y patrimonialización cultural que influyen en los discursos de identidad nacional (Sanín Santamaría, J. D. (2010). Made in Colombia. La construcción de la colombianidad a través del mercado. Revista Colombiana de Antropología, 46(1)).

6. Los imaginarios y las representaciones se producen en un flujo continuo que cambia de dirección constantemente, produciéndose una estrecha relación de reciprocidad o de contradicción entre los mismos en una dinámica natural.

7. Future Brand, empresa consultora de marca a nivel mundial. Cuya misión es: "ser la consultora creativa líder mundial para una experiencia de marca de futuro. Esto es lo que nos ayuda a enfocar nuestros esfuerzos y ser el mejor socio posible para nuestros clientes al servicio de la creación de un futuro más positivo".

8. Consulta web: http://www.achijirawaa.co

9. Entrevista a Armando Silva, consultada en Mujica, www.bifurcaciones.cl, 2005.

10. Red Dircom Iberoamericana es un proyecto red que extrapola en América Latina lo que en Europa había logrado las empresas, Instituciones y Organizaciones, necesitadas de una nueva concepción directiva esencialmente estratégica e integradora para la era de las telecomunicaciones, la economía de la Información y la sociedad del conocimiento. Necesitábamos una nueva visión holística, transversal y a la vez sistémica, surgida de la revolución cibernética que a mitad del siglo XX venía a superar los viejos modelos del pasado. La semilla ibérica en América Latina, la lengua y la cultura compartidas tenían que llevar a la comunidad hispano hablante, el neohumanismo europeo en la gestión y la eficacia de las empresas, que contrasta con el modelo capitalista fundamentalista de Wall Street que ya vemos a donde nos ha llevado, y con la robotización nipona de las personas en un sistema entre capitalismo y comunismo, ambos fracasados. http://www.reddircom.org/proyecto.php 11. La Agencia de Informaciones de USA provee una definición amplia desde la Diplomacia Pública: "La influencia de las actitudes públicas en la formación y ejecución de la política exterior. Comprende dimensiones de las relaciones internacionales, más allá de otros países; la interacción de grupos privados de interés con sus pares en otros países; el reporte de los asuntos internacionales y su impacto en la política exterior; la comunicación entre aquellos cuya labor es la comunicación, como es el caso de los diplomáticos y corresponsales extranjeros; y los procesos de comunicación intercultural" (Anholt, 2007). 12. Motta retoma el estudio de Claudio Varini realizado en 1994: Una ruta de acercamiento al espacio y la arquitectura de los indígenas Embera y Waunana. En Reportes de Investigación No. 4 PUJ, Bogotá. 


\section{Referencias bibliográficas}

Abric, J.-C. (2001). Prácticas sociales y representaciones. México: Ediciones Coyoacán, 227 pp. Aceves Lozano, J. E. (2001). Experiencia biográfica y acción colectiva en identidades emergentes. Espiral, 7(20).

Aicher, O., \& Mielke, J. C. (1994). El mundo como proyecto. G. Gili.

Agamben, G. (2015). ¿ Qué es un dispositivo?: seguido de El amigo; y de La Iglesia y el Reino. Editorial Anagrama.

Anholt, S. (2007). Competitive identity. The new brand management for nations, cities andregions. London: Palgrave Macmillan.

Arnheim, R., \& Arnheim, R. (1985). El pensamiento visual (No. 159.93). Paidós.

Arnheim, R. (1998). El poder del centro. Madrid, España: Alianza editorial.

Aumont, J. (1990). La imagen. Barcelona, España: Paidós Ibérica.

Bhabha, H. K. (1995). Cultural diversity and cultural differences. na.

Arfuch, L. (2006). Las subjetividades en la era de la imagen: de la responsabilidad de la mirada. Educar la mirada: políticas y pedagogías de la imagen, 75-84.

Balandier, G. (1992). El poder de las escenas. De la representación del poder al poder de la representación. Barcelona. Paidós.

Bertorello, A. (2005). Semiosfera y Mundo: ensayo sobre un posible diálogo entre Lotman y Heidegger. la Revista LSD: Lenguaje, Sujeto y Discurso, 15-19.

Bourdieu, P. (2006). La identidad y la representación: elementos para una reflexión crítica sobre la idea de región (Análisis).

Bourriaud, N. (2006). Estética relacional. Buenos Aires: Adriana Hidalgo, editora.

Brea, J. L. (2005). Los estudios visuales: por una epistemología política de la visualidad. In Estudios visuales: la epistemología de la visualidad en la era de la globalización (pp. 5-14). Akal. Consultado en: https://es.scribd.com/document/333172459/BREA-Jose-LuisEstudios-Visuales-Epistemologia-de-la-Visualidad-pdf.

Bruner, J. S., \& Linaza, J. L. (1984). Acción, pensamiento y lenguaje (Vol. 1). Madrid: Alianza.

Castells, M. (1997). La era de la información: economía, sociedad y cultura. Vol. 2 el poder de la identidad. 44121 CIC-UCAB/0392 20040218 GR.

Castells, M. (1998). Espacios públicos en la sociedad informacional. Ciutat real, ciutat ideal. Significat i funció a l'espai urbà modern.

Castells, M. (1998). Paraísos comunales: identidad y sentido en la sociedad red. La era de la información. Economía, sociedad y cultura, 2, 27-90.

Castoriadis, C. (1986). Los dominios del hombre. Barcelona, España: Gedisa.

Chavez, N. (2001). El oficio de diseñar: propuestas a la conciencia crítica de los que comienzan. Barcelona, Gustavo Gili SA.

Costa, J. (2003). Diseñar para los ojos (Vol. 1). Universidad De Medellin.

Dinnie, K. (2008). Nation branding. concepts, issues, practice. Oxford: Butterworth-Heinemann.

Echeverri, L. M., \& Rosker, E. (2011). Diferencias en la construcción de marca país: Canadá y Colombia. Revista Virtual Universidad Católica del Norte, (33).

Echeverri, L. M., \& Trujillo, L. (2014). Marca País Experiencias en América Latina y la realidad en Colombia. Colegio de Estudios Superiores de Administración, CESA. 
Echeverri, L. M., Estay-Niculcar, C. A., \& Rosker, E. (2012). Estrategias y experiencias en la construcción de marca país en América del sur. Estudios y perspectivas en turismo, 21(2), 288-305.

Foucault, M. (1988). El sujeto y el poder. Revista mexicana de sociología, 50(3), 3-20.

Frascara, J. (1997). Diseño gráfico para la gente-Comunicación de masas y cambio social. Buenos Aires, Argentina: Ediciones Infinito.

Heller, E. (2004). Psicología del color. España: Gustavo Gili. Losada, Ed.(1975). Curso de lingüística general, Buenos Aires, Argentina.

Gobe, M. (2010). Emotional Branding, Revised Edition: The New Paradigm for Connecting Brands to People. Random House Digital, Inc.

Gombrich, E. H., Hochberg, J., \& Black, M. (1983). Arte, percepción y realidad. Paidós.

González Solas, J. (2004). La identidad visual. Área abierta, (8), Not-availabe.

Govers, R., \& Go, F. (2009). Place branding: Glocal, virtual and physical identities, constructed, imagined and experienced. Springer. Palgrave, US.

Guigou, L. N. (2001). El ojo, la mirada: Representación e imagen en las trazas de la Antropología Visual. Diverso Revista de Antropología Social, 4, 123-134.

Haesbaert, R., \& Canossa, M. (2011). El mito de la desterritorialización: del "fin de los territorios" a la multiterritorialidad. Mexico: Siglo XXI.

Hall, S. (2010). Etnicidad: identidad y diferencia. Sin garantía. Trayectorias y problemáticas en los.

Henao Castro, A. F., \& Rodríguez Sánchez, N. (2006). "Sobre el Concepto de Estado: El debate contemporáneo" (On the Concept of the State: The Current Debate).

Hobsbawm, E. J. (1993). Identidad. Conferencia inaugural del congreso "Los Nacionalismos en Europa: Pasado y Presente". Santiago de Compostela, 27-29 de septiembre de 1993. Hobsbawm, E. J. (1994). Identidad.

Ibáñez Angulo, M. (2008). De la identidad nacional a la ciudadanía trasnacional: procesos migratorios y espacios trasnacionales. En línea. Consultado el 02/05/09. Disponible en: http://docsgedime.files.wordpress.com/2008/02/monicaibanez.pdf)

Maya Gallego, M. (2007). Las fronteras socio-culturales y la cuestión de la identidad del territorio. Revista electrónica de Humanidades y Cs. Sociales del Departamento de Humanidades de la U. Tecnológica Metropolitana, (UTEM), Stgo, Chile. Recuperado de http://www.utem.cl/thelos/articulo_n2_01.htm

Jodelet, D. (2000). Representaciones sociales: contribución a un saber sociocultural sin fronteras. Develando la cultura. Estudios en representaciones sociales. México, DF: UNAM, 7-30.

Klein, N. (2013). No Logo. El poder de las Marcas. Ed. Paidós.

Lacan, J. (1974). Seminario 22. “R.S.I.” México D.F., México: Siglo XXI.

Ledesma, M. (2010). El giro icónico. In Ponencia presentada en el Primer simposio internacional interdisciplinario Aduanas del Conocimiento. "La traducción y la constitución de las disciplinas entre el Centenario y el Bicentenario".

Lipovetsky, G. (2000). Era del vacío. Barcelona: Anagrama.

López, E., \& Enrique, J. (2004). Del sujeto a la agencia (a través de lo político). Athenea Digital. Revista de pensamiento e investigación social, (5).

Magariños De Morentin, J. (2001). La (s) semiótica (s) de la imagen visual. Cuadernos de la Facultad de Humanidades y Ciencias Sociales. Universidad Nacional de Jujuy, (17), 295-320. 
Margolin, V. (2012). Las políticas de lo artificial: ensayos y estudios sobre diseño. DR Editorial Designio.

Margolin, V. (2015). Un “modelo social” de diseño: cuestiones de práctica e Investigación. Revista Kepes, 61-71.

Martín Barbero, J. (1999). De los medios a las mediaciones. Comunicación, cultura y hegemonía. Bogotá.

Melissen, J. (2005). The New Public Diplomacy. Soft Power in International Relations. Palgrave Macmillan.

Merleau-Ponty, M., \& Cabanes, J. (1975). Fenomenología de la percepción (p. 475). Península.

Mitchell, W. J. T. (2003). Mostrando el ver. Estudios visuales.

Moreno, J. D., \& Moons, T. (2002). Representaciones sociales, identidad y cambio [Social representations, identity and change]. Redes, 10, 51-69.

Moscovici, S. (1982). The coming era of representations. In Cognitive analysis of social behavior (pp. 115-150). Springer Netherlands.

Moscovici, S.(1984). “The penomenon of social representations”. En Farr, R. M. y Moscovici, S., comps. Social representations. Cambridge, University Press.

Motta González, N. (2014). Territorios e identidades. Historia y Espacio, 2(26), 91-109.

Muñoz, G. (2006). La comunicación en los mundos de vida juveniles: hacia una ciudadanía comunicativa. Tesis CINDE, Universidad de Manizales.

Nancy, J. L. (2006). La imagen: mimesis \& methexis. Escritura e imagen, 2, 7-22.

Nancy, J. L. (2007). La comunidad enfrentada. Buenos Aires: Ediciones La Cebra.

Nye, J. (2004). Soft power. The means to success in world politics. New York. Public Affairs.

Ochoa, C. G., \& Maya, R. T. (2012). Diseño y consumo en la sociedad contemporánea. Designio.

Olins, W. (2002). Branding the nation: the historical context, en Morgan, N. et al., Destination Branding: Creating the unique destination proposition. Oxford: Butterworth-Heinemann, pp. 17-25.

Oyarbide, M. A. (2004). Jerome Seymour Bruner: de la percepción al lenguaje. Revista Iberoamericana de Educación (ISSN: 1681-5653).

Páez, D. (1991). "Los jóvenes y el consumo de alcohol. Un estudio sobre representaciones sociales”. Univ. del País Vasco. Departamento de Psicología Social y Metodología. Moreno, J. D., \& Moons, T. (2002). Representaciones sociales, identidad y cambio [Social representations, identity and change]. Redes, 10, 51-69.

Papanek, V. (1977). Diseñar para el mundo real: ecología humana y cambio social. Ciencia, Tecnología, Sociedad/Dirg. por Luis A. Fernández-Galiano.

Quijano, A. (2000). Colonialidad del poder, eurocentrismo y América Latina.

Quijano, A. (2010). América Latina: hacia un nuevo sentido histórico. Suma Kawsay/Buen Vivir y cambios civilizatorios, 2da. Ed., Coord. Irene León, FEDAEPS, Quito, 201, P. 55-71.

Requena, J. (1988). El discurso televisivo. Espetáculo de la posmodernidad. Espanha: Cátedra.

Renaud, A. (1990). Comprender la imagen hoy. Nuevas Imágenes, nuevo régimen de lo visible, nuevo Imaginario. En Videoculturas de fin de siglo, Signo e Imagen. Madrid, España: Cátedra.

Reyes, Z., \& Giovanna, D. (2008). Nación, identidad y ciudadanía: del ejercicio de inclusión al de exclusión. CS, (2), 165-180. 
Robertson, R., \& Pineda, M. (1998). Identidad nacional y globalización: falacias contemporáneas. Revista Mexicana de Sociología, 3-19.

Sassen, S. (2001). ¿Perdiendo el control?: la soberanía en la era de la globalización.

Sienra Chaves, S., Pérez García, A., Rodríguez Torres, L., \& Mojica Arias, j. U. A. N. (2014). La imagen como pensamiento.

Silva, A. (2004). Imaginarios urbanos: hacia la construcción de un urbanismo ciudadano. Metodología. Convenio Andrés Bello, Universidad Nacional de Colombia.

Silva, A. (2012). Imaginarios urbanos. Tercer Mundo Editores.

Silva, A. (2014). Imaginarios, el asombro social. U. Externado de Colombia.

Solas, J. G. (2012). El espacio público como lugar político del diseño y del arte. Arte y Ciudad, (2), 5-16.

Van Ham, P. (2005). Branding European power. Journal of Place Branding 1 (2). 122-126.

Van Ham, P. (2008). Place branding. The state of the art. The Annals of the American Academy of Political and Social Science, 616, 126-149.

Varini, C. (1994). Hábitat arquitectura y entorno de los embera y waunana. Geografía Humana de Colombia, variación biológica y cultural en Colombia, 1.

Vicente, A., \& Moreno, M. T. (2009). Identidad nacional: planteamiento y evaluación de un modelo estructural. Revista Obets, (3), 19-30.

Wang, J. (2005). Localising public diplomacy. The role of sub-national actors in nation branding. Place Branding, 2. 53-67.

\begin{abstract}
The image-representation, socially accepted and without further mediation, as symbol of recognition of the real world, has a sign of visual identity that unfolds in multiple aspects and capabilities: identifies, differences, protects interests, interact socially and is speech of interests and different strategies. Taken as a substitute for reality, the brand is one of the images articulated with greater coverage in the contemporaneity, it comprises in addition to commercial entities, territories and subjects.
\end{abstract}

Keywords: Image - representation- diversity - alterity - identity

Resumo: A representação da imagem, socialmente aceita e sem posterior mediação, como símbolo de re conhecimento do mundo real, tem na marca ou logotipo um sinal de identidade visual que se desdobra em múltiplos aspectos e capacidades: identifica, diferencia, protege interesses, interage socialmente e é um discurso que interessa e estratégias subjacentes de natureza diferente. Assumindo como um substituto para a realidade, a marca é uma das imagens articuladas com maior abrangência na contemporaneidade, inclui também entidades comerciais, os territórios, os sujeitos, sua identidade e suas ações por meio de homogeneizações no marco do sistema capitalista, tornando-se fortes ferramentas de poder. Atualmente este sinal é figuração, reificação; talvez mais complexo, porque mediado pelas tecnologias da imagem, não substitui uma realidade, simula-o, antecipa-o mesmo da sua inexistência, dando origem a formas inovadoras de dominação simbólica que tendem à diversidade, acentuando a negação da "alteridade". Nesta relação com o ter- 
ritório, o mercado e suas marcas, o indivíduo fim de s. XX e s iniciais XXI, construiu novas relações com o visível que moldam novas formas de identidade e tornam possível tanto a submissão quanto a emergência de resistências.

Palavras chave: Imagem - representação - diversidade - alteridade - identidade.

[Las traducciones de los abstracts fueron supervisadas por el autor de cada artículo] 